\title{
IATROGENIC AND ODONTOGENIC FORMS OF STOMATOGENIC MAXILLARY SINUSITIS. ULTRASOUND CHARACTERISTIC
}

\author{
Suren Varzhapetyan \\ Department of Surgical and Preventive Dentistry \\ SE «Zaporizhzhia Medical Academy of Postgraduate Education of MHP of Ukraine» \\ 20 Vintera blvd., Zaporozhye, Ukraine, 69096 \\ suren-wargapetyan@rambler.ru
}

\begin{abstract}
The special features of transfer of information of the cone-beam computed tomography allows make conclusions about the character of pathological changes in maxillary sinuses only by the features of form and outlines of shadow of changed mucous tunic of sinus at its equal intensity that often leads to the incorrect interpretation of the results of research.

The high sensitivity of two-dimensional ultrasonography as for thickening (sclerosis) of mucous tunic, its edema (effusion) and exudation (purulent or serous) allows the more widen use of this method in addition to the cone-beam tomography at examination of maxillary sinuses. The other important moment is an absence of harmful influence of ultrasound on organism that makes it ideal for assessment of the dynamics of clinical course and allows prescribe it for pregnant and children.

The two-dimensional ultrasound examination of 86 patients with stomatogenic maxillary sinusitis (iatrogenic - 79,1 \% odontogenic $-20,9 \%$ forms) was carried out using ultrasound diagnostic apparatus ACUSON X 500, ATSmod.539 (SIEMENS, USA) in B-mode by the method of V. V. Shilenkova.

In the result of research was found out that sonographic picture of the maxillary sinuses at stomatogenic maxillary sinusitis depends on etio-pathogenetic form of disease. For iatrogenic form of maxillary sinusitis of stomatogenic origin are typical the ultrasound signs of chronic inflammation with many inflammatory inclusions in sinus, sclerosis of mucous tunic and serous effusion. By frequency prevailed: hyperechogenicity of membrane (30,8\%), its heterogenous echostructure (52,9\%), hyperechogenic character of content $(39,7 \%)$, arched outline of the back wall $(36,8 \%)$.

For odontogenic form of maxillary sinusitis of stomatogenic origin are typical the ultrasound signs of acute catarrhal inflammation with predomination of exudation in the mucous tunic and absence of contents in the lumen of sinus. By frequency prevailed: hypoechogenicity of membrane (27,8\%), its homogenous echostructure (45,6\%); acoustic shadow in sinus (72,2 \%), arched outline of the back wall $(27,8 \%)$.
\end{abstract}

Keywords: stomatogenic maxillary sinusitis, iatrogenic sinusitis, odontogenic sinusitis, ultrasound diagnostics.

\section{Introduction}

The recent data of literature indicate the predominance of iatrogenic etiologic factors of in the development of maxillary sinusitis [1]. The clinical examination remains the main method of revelation of symptoms of inflammatory injury of maxillary sinuses [2, 3]. Already at the primary medical examination of patient taking into account his complaints, specificity of anamnesis of the development of disease, the special features of the clinical picture it is possible to make the primary differentiation of the form of maxillary sinusitis, to plan the further purposeful examination according to the received results $[4,5]$.

Undoubtedly, the most effective additional method of examination of maxillary sinuses is computed tomography, especially, the digital cone-beam tomography [6, 7]. Our researches proved the opinions of certain authors about the possible mistakes at determination of pathologic changes of the mucous tunic of the maxillary sinuses according to the CBCT, because one must make conclusions about these changes only by the features of form and outline of the shadow of changed mucous tunic at its equal intensity.

The high sensitivity of two-dimensional ultrasonography as for thickening (sclerosis) of mucous tunic, its edema (effusion) and exudation (purulent or serous) allows the more widen use of this method in addition to the cone-beam tomography at examination of maxillary sinus- 
es [8]. The other important moment is an absence of harmful influence of ultrasound on organism that makes it ideal for assessment of the dynamics of clinical course and allows prescribe it for pregnant and children.

The clinical studies of paranasal sinus by ultrasound were started in 70ies in USA, Germany, Finland and are continued for today. The indices of sensitivity and specificity of ultrasound examination of paranasal sinuses were compared with the results of puncture or plain radiography of paranasal sinuses, the received results were contradictory [9] that caused the further researches in this field.

In the results of her studies Zasteba T. A. rather completely "deciphered" the ultrasound criteria of the different pathological changes in the lumen of sinus [10]. Further the attention of clinicians was attracted to the informativeness of two-dimensional ultrasound method of examination of maxillary sinuses, study of its diagnostic value $[8,11]$ and the features of ultrasound diagnostics of rhinosinusites in children [2].

Generalizing the literature data, the advantages of ultrasound method of examination of maxillary sinuses can be expressed in the main propositions:

1) harmfulness for the health of patient;

2) rapidity of examination;

3) economy, low cost;

4) it can be carried out not only by the specialists of ultrasound diagnostics but by the family doctors;

5) satisfactory quality of visualization is provided even using the portative scanners;

6) possibility to realize examination at home, near the bed of patient;

7) the pus, liquid that contains detritus is analyzed better at ultrasound due to the presence of faint internal echo-signal [8, 12-15].

The native authors note that this method did not find its wide application in Ukraine for today, despite its diagnostic informativeness, that can be compared with radiography [15]. 10 years ago it could be caused by economic (the abundance of ultrasound equipment was comparable with radiographic one) and technical (the bulkiness of apparatuses, low resolving power, imperfection of software, use of A-method of scanning) complications [16]. For today the main problem is an absence of introduction of the method into practice.

Analysis of the foreign literature demonstrated that despite the rich history of study of the two-dimensional sonography method in diagnostics of pathologies of maxillary sinuses, information about the features of the use of this method at stomatogenic maxillary sinuses is absent. The study of sonographic image of these pathological states needs attention within the research devoted to the inflammatory diseases of the maxillary sinuses. The received data can favor the widening of the application of ultrasound method of examination in clinical stomatology and rise of effectiveness of diagnostics of the maxillary sinuses that is the aim of our research.

\section{Aim of research}

To raise the effectiveness of diagnostics of stomatogenic maxillary sinusitis.

\section{Material and methods of research}

Ultrasonography of the maxillary sinuses was made to 86 patients $28-65$ years old (mean age 40,4 $\pm 3,2$ years), with clinical signs of maxillary sinusitis using the ultrasound diagnostic apparatus ACUSON X 500, ATSmod.539 (SIEMENS, USA) in B-mode by the method of V. V. Shilenkova [2]. The primary examination of patients allowed reveal the cause and effect relation between the inflammation in maxillary sinus and treating manipulations - iatrogenic sinusitis - in $68(79,1 \%)$ patients. The cause of development of maxillary sinusitis in $18(20,9 \%)$ patients was the spread of infection from the chronic periapical nidus of teeth that were not treated earlier - odontogenic form of stomatogenic maxillary sinusitis.

The assessment of pathological changes in sinuses was carried out on the following indices:

- thickness ( $\mathrm{mm})$ and echogenicity of the soft tissues of infraorbital region, above the front wall of sinus; 
- thickness (mm) and integrity of the front bone wall of sinus;

- thickness (mm) of mucous tunic of maxillary sinus;

- echogenisity, uniformity of thickening of the mucous tunic of sinus;

- visualization of the contents of sinus (acoustic shadow, small or coarse hyper- and hypoechogenic inclusions, liquid level, cyst);

- visualization of the back wall of sinus;

- form of outline of the back wall of sinus (straight-line or even, round or oval).

Echogenicity of the object was determined subjectively and depended on its acoustic properties (sound conduction, reflection, refraction and absorption of sound waves), that in its turn are determined by the morphologic structure of object. The general regularity of interconnection between ultrasound and morphologic structure of tissue is the following: the less liquid in structure, the higher its echogenicity, and vice versa, the higher the liquid content - the lower echogenicity [17].

In the healthy sinus is usually observed the effect of ultrasound "shadow". Visualization of the back wall is possible only at disorder of pneumatization of sinus and depends on the amount of fluid or other contents $[11,16]$. Ultrasound sign of edema of the mucous tunic are the region of lowered echogenisity and heterogenous structure. The fluid is determined as the even lowering of echogenicity with hyperechogenic point inclusions or straight-line partitions of horizontal or ellipse form. The two-dimensional ultrasound allows visualize the edema with thickness from $0,5 \mathrm{~mm}$ that is an undoubted advantage of the method [16].

The scanning of maxillary sinuses was carried out by the specialist of ultrasound diagnostics.

The results in Table 3-5 are presented in the absolute values (abs.), in parts (percents) and in errors of parts.

The statistical analysis of the absolute values of tats was carried out by Student's method and comparison of parts - by $\chi^{2}$ method.

\section{Results of research}

Anechogenic formations are the liquid ones. Anechogenic round shadow with distinct outlines connected with mucous tunic with heterogenous content as hyperechogenic suspension attended with an effect of distal strengthening is considered as echographic sign of cyst, (Table 1). As opposite to cyst, polyps are visualized as inclusions that have ellipse or oval form, without echographic signs of the liquid components (hypererchogenic) [2].

Table 1

Sonographic indices of pathological changes in maxillary sinus

\begin{tabular}{ccc}
\hline № & Sonographic index & Character of pathological changes in sinus \\
\hline 1 & Parts of lowered echogenicity with heterogenous echostructure & Edema of mucous tunic \\
2 & Hypoechogenic contents with hyperechogenic point inclusions & Inflammatory fluid in sinus \\
3 & Round anechogenic shadow with distinct outlines & Cyst \\
4 & Hyperechogenic ellipse or oval inclusions without & Polyps
\end{tabular}

At acute catarrhal sinusitis the outline of back wall has the oval form- exudation replicates anatomic form, and at purulent maxillary sinusitis - the straight-line one that is probably caused by the fact that the purulent content creates conditions for the more even damping of ultrasound wave because of its density $[10,11]$ (Table 2).

In the Table 3 are given the results of the scanning of shadows of infraorbital shadow that corresponds to the front wall of maxillary sinus on the healthy and injured side in patients with iatrogenic and odontogenic maxillary sinusitis. 
Table 2

Sonographic indices of purulent and catarrhal (serous) maxillary sinusitis

\begin{tabular}{cccc}
\hline No & Studied sonographic index & \multicolumn{2}{c}{ Clinical form of acute maxillary sinusitis } \\
& Thickness of mucous tunic of sinus & Up to $12 \mathrm{~mm}$ & Up to $8 \mathrm{~mm}$ \\
1 & Echogenicity & Gently raised & Significantly raised \\
2 & Echostructure & Homogenous & Heterogenic \\
4 & Thickening & Even & Even, straight-line
\end{tabular}

Table 3

Ultrasound characteristic of tissues on projection of the front wall of maxillary sinus

\begin{tabular}{|c|c|c|c|c|c|c|}
\hline \multirow[t]{2}{*}{ № } & \multirow[t]{2}{*}{ Studied sonograpic signs } & \multicolumn{2}{|c|}{$\begin{array}{l}\text { Iatrogenic } \\
\text { maxillary sinusitis } n=68\end{array}$} & \multicolumn{2}{|c|}{$\begin{array}{l}\text { Odontogenic } \\
\text { maxillary sinusitis } n=18\end{array}$} & \multirow[b]{2}{*}{$\mathbf{P}$} \\
\hline & & abs. & $\mathbf{P} \pm \mathbf{S p}$ & abs. & $\mathbf{P} \pm \mathbf{S p}$ & \\
\hline 1 & $\begin{array}{l}\text { Mean index of difference of thickness of soft tissues in } \\
\text { infraorbital region of healthy and injured sinus }\end{array}$ & $0,5 \mathrm{~mm}$ & $3,9 \pm 2,3$ & $1,1 \mathrm{~mm}$ & $8,4 \pm 6,5$ & $\mathrm{p}>0,05$ \\
\hline 2 & Thickness of the front bone wall (mm) & $1,1 \pm 0,3$ & - & $1,1 \pm 0,3$ & - & $\mathrm{p}>0,05$ \\
\hline 3 & Disturbance of integrity of the front bone wall & 1 & 1,6 & - & - & - \\
\hline 4 & $\begin{array}{l}\text { Difference of thickness of mucous tunic of the healthy } \\
\text { and injured sinus }\end{array}$ & $2,7 \pm 0,4 \mathrm{~mm}$ & $28,1 \pm 5,4$ & $\begin{array}{l}3,7 \pm 0,4 \\
\mathrm{~mm}\end{array}$ & $35,2 \pm 11,2$ & $\mathrm{p}<0,05$ \\
\hline
\end{tabular}

Note: abs. - absolute value of scanned sinuses; P-part in \% of all scanned sinuses in group; Sp-error of part; $p$ - reliability of difference of indices in studied groups, significant at $\leq 0,05$

Qualitative characteristics of the mucous tunic of maxillary sinuses in patients with the main forms of stomatogenic sinusitis that indicate the character of pathological changes are presented in the Table 4.

Table 4

Ultrasound characteristic of the structure of mucous tunic of maxillary sinus

\begin{tabular}{|c|c|c|c|c|c|c|}
\hline \multirow[t]{2}{*}{ № } & \multirow[t]{2}{*}{ Studied sonographic signs } & \multicolumn{2}{|c|}{$\begin{array}{c}\text { Iatrogenic } \\
\text { maxillary sinus } n=68\end{array}$} & \multicolumn{2}{|c|}{$\begin{array}{c}\text { Odontogenic } \\
\text { maxillary sinus } n=18\end{array}$} & \multirow[b]{2}{*}{$\mathbf{P}$} \\
\hline & & abs. & $\mathbf{P} \pm \mathbf{S p}$ & abs. & $\mathbf{P} \pm \mathbf{S p}$ & \\
\hline 1 & Hypoechogenic mucous tunic & 12 & $17,6 \pm 4,6$ & 5 & $27,8 \pm 10,5$ & $\mathrm{p}>0,05$ \\
\hline 2 & Hyperechogenic mucous tunic & 27 & $39,7 \pm 5,9$ & 3 & $16,7 \pm 8,5$ & $\mathrm{p}>0,05$ \\
\hline 3 & Isoechogenic mucous tunic & 25 & $36,8 \pm 5,7$ & 8 & $44,4 \pm 11,7$ & $\mathrm{p}>0,05$ \\
\hline 4 & No visualization of mucous tunic & 4 & $5,8 \pm 2,8$ & 3 & $16,7 \pm 8,5$ & $\mathrm{p}>0,05$ \\
\hline
\end{tabular}

Note: abs. - absolute value of scanned sinuses; $P$ - part in \% of all scanned sinuses in group; Sp - error of part; $p$-reliability of difference of indices in studied groups, significant at $\leq 0,05$

Echostructure of mucous tunic of maxillary sinuses of $36(52,9 \pm 6,0 \%)$ patients with iatrogenic sinusitis was assessed as homogenous (Table 5), in $31(45,6 \pm 6,0 \%)$ - as heterogenous. These criteria in the group of odontogenic sinuses were revealed in $4(22,2 \pm 9,7 \%)$ and $11(61,1 \pm 11,4 \%)$ cases respectively. The mucous tunic was not visualized in $1(1,5 \%)$ sinus in the group of iatrogenic sinusitis and in $3(16,7 \%)$ sinuses in the group of odontogenic sinusitis.

Criteria of contents in the lumen of sinus, thickening of mucous tunic and form of the outline of the back wall of sinus are given in the Table 5. 
Table 5

Ultrasound characteristic of structure and thickness of mucous tunic and contents of maxillary sinuses

\begin{tabular}{|c|c|c|c|c|c|c|}
\hline \multirow[t]{2}{*}{ № } & \multirow[t]{2}{*}{ Studied sonographic signs } & \multicolumn{2}{|c|}{$\begin{array}{c}\text { Iatrogenic } \\
\text { maxillary sinusitis } n=68\end{array}$} & \multicolumn{2}{|c|}{$\begin{array}{c}\text { Odontogenic } \\
\text { maxillary sinusitis } n=18\end{array}$} & \multirow[b]{2}{*}{$\mathbf{P}$} \\
\hline & & abs. & $\mathbf{P} \pm \mathbf{S p}$ & abs. & $\mathbf{P} \pm \mathbf{S p}$ & \\
\hline 1 & Heterogenous echostructure of mucous tunic of sinus & 36 & $52,9 \pm 6,0$ & 4 & $22,2 \pm 9,7$ & $\mathrm{p}<0,05$ \\
\hline 2 & Homogenous echostructure of the mucous tunic of sinus & 31 & $45,6 \pm 6,0$ & 11 & $61,1 \pm 11,4$ & $\mathrm{p}>0,05$ \\
\hline 3 & Even thickening of the mucous tunic of sinus & 36 & $52,9 \pm 6,0$ & 5 & $27,8 \pm 10,5$ & $\mathrm{p}<0,05$ \\
\hline 4 & Uneven thickening of the mucous tunic of sinus & 18 & $26,5 \pm 5,3$ & 2 & $11,1 \pm 7,4$ & $\mathrm{p}>0,05$ \\
\hline 5 & Hypoechogenic Contents of sinus & 2 & $3,0 \pm 2,0$ & 1 & $5,5 \pm 5,1$ & $\mathrm{p}>0,05$ \\
\hline 6 & Hyperechogenic contents of sinus & 24 & $35,3 \pm 5,7$ & 1 & $5,5 \pm 5,1$ & $\mathrm{p}<0,05$ \\
\hline 7 & Liquid in sinus & 44 & $64,7 \pm 5,7$ & 7 & $38,9 \pm 11,5$ & $\mathrm{p}<0,05$ \\
\hline 8 & Acoustic shadow & 25 & $36,8 \pm 5,8$ & 13 & $72,2 \pm 10,5$ & $\mathrm{p}<0,05$ \\
\hline 9 & Even outline of the back wall of sinus & 17 & $25,0 \pm 5,2$ & 2 & $11,1 \pm 7,4$ & $\mathrm{p}>0,05$ \\
\hline 10 & Arched outline of the back wall of sinus & 27 & $39,7 \pm 5,9$ & 5 & $27,8 \pm 10,5$ & $\mathrm{p}>0,05$ \\
\hline
\end{tabular}

Note: abs. - absolute value of scanned sinuses; $P$ - part in \% of all scanned sinuses in group; Sp - error of part; $p$-reliability of difference of indices in studied groups, significant at $\leq 0,05$

\section{Discussion of the received results}

According to the literature data, the thickness of maxillary sinus in healthy adults is 1,0-1,5 mm (Rivin D, 1967). The scientists who study the effectiveness of ultrasound method of examination at rhinosinusites note that sonographically received thickness of membrane exceeds its true sizes because echosignals reflected from air around the mucous tunic also take part in creation of echocomplex of signals reflected from the mucous tunic. According to their data, the thickness of mucous tunic of healthy sinuses at ultrasound reaches $4,74(+0,42) \mathrm{mm}[10]$. The authors note that at catarrhal form of sinusitis the mucous tunic thickens up to no less than $12 \mathrm{~mm}$, whereas at the purulent form - up to $8 \mathrm{~mm}$ only (Table 1).

At catarrhal form of acute sinusitis prevails the moderate rise of echogenicity and at the purulent one echogenicity is significantly raised. Echostructure of the mucous tunic at acute catarrhal inflammation is more often homogenous and at the acute purulent one - usually heterogenous. At acute catarrhal sinusitis the mucous tunic tends to the even thickening. And at acute purulent process it always thickens unevenly [10].

In patients with odontogenic maxillary sinus the thickness of soft tissues in infraorbital region above the injured sinus $(13,1 \pm 1,5 \mathrm{~mm})$ reliably exceeded the value of this index in patients with iatrogenic sinusitis $(12,3 \pm 1,2 \mathrm{~mm}), \mathrm{p}<0,05$. Both indices were within norm given in literature [10].

On the average at iatrogenic maxillary sinusitis the thickness of mucous tunic that covers the internal surface of injured sinus was by $2,7 \pm 0,4 \mathrm{~mm}$ more than on the healthy side (Table 3). At odontogenic sinusitis this difference was by $27,0 \%$ more $-3,7 \pm 0,4 \mathrm{~mm},(\mathrm{p}<0,05)$.

Ultrasound indices of the state of mucous tunic of maxillary sinuses at both odontogenic $(44,4 \pm 11,7 \%)$ and iatrogenic $(36,8 \pm 5,7 \%)$ sinuses more often indicated the absence of pathological changes in its depth that corresponded to isoechogenic signal. But at odontogenic sinusitis hypoechogenicity of membrane $(27,8 \pm 10,5 \%)$, caused by effusion and exudation was fixed more often than hyperechogenicity $(16,7 \pm 8,5 \%)$ - the result of sclerosis. At iatrogenic sinusitis hyperechogenic mucous tunic $(39,7 \pm 5,9 \%)$ prevailed over hypoechogenic one $(17,6 \pm 4,6 \%)$, and was revealed in almost 1,5 times more often than at odontogenic sinusitis $(p>0,05)$. That is at iatrogenic maxillary sinusitis prevailed sonographic picture of chronic mucositis with phenomena of sclerosis and at odontogenic in sinuses were more often observed the signs of acute inflammation and exudation in the depth of mucous tunic (Table 4).

The chronic mucositis leads to the formation of free fluid in the lumen of maxillary sinus and hyperecogenic inclusion of the different form mosaic structure, that consists of detritus, fibrin tenias, different foreign bodies of inflammatory origin and other elements of exudation adding 
heterogeneity of echosructure to the mucous tunic of sinus [11]. Analysis by the $\chi^{2}$ method demonstrated that at iatrogenic sinusitis the heterogeneity of echostructure of the mucous tunic of sinus revealed in $36(52,9 \pm 6,0 \%)$ patients reliably exceeded the frequency of occurrence of this criterion in patients with odontogenic sinusitis - revealed in $4(22,2 \pm 9,7 \%)$ sinuses, $p<0,05$. At odontogenic sinusitis homogenous echostructure of mucous tunic - indicator of catarrhal (serous) inflammation was revealed more often $(61,1 \pm 11,4 \%)$, than at iatrogenic form $(45,6 \pm 6,0 \%)$. For iatrogenic sinusitis was more typical the hyperechogenic character of contents $(35,3 \pm 5,7 \%), p<0,05$.

The results of ultrasound examination indicate the predominance of cases of revelation of unchangeable sinus (acoustic shadow $-61,1 \pm 11,4 \%$; even thickening of the mucous tunic of sinus $-27,8 \pm 10,5 \%)$ at odontogenic sinusitis $(\mathrm{p}<0,05)$. The cause of odontogenic form of stomatogenic maxillary sinusitis is the untreated teeth of maxilla that is the absence of sanitation of oral cavity. Clinical studies prove the expressiveness of sigs of acute inflammation at this form. The young age of contingent $(35,3 \pm 2,4$ years) comparing with patients with iatrogenic $(45,5 \pm 1,2$ years) stomatogenic sinusitis indicates the early manifestation of disease that quite can be the cause of absence of the expressed changes in sinus - appendages of chronic inflammation and expressiveness of acute sinusitis. The medical manipulations in "causal" teeth favor the long-term remission and latter manifestation of iatrogenic sinusitis [18]. The long asymptomatic course, periodical exacerbations are the causes of sclerosis of the mucous tunic and formation of polyps, detritus and fibrin tenias in sinus that form the aforesaid feature of sonographic picture of iatrogenic sinusitis. At iatrogenic sinusitis in the lumen of sinus prevails hyperechogenic suspension $(35,3 \pm 5,7 \%)$, as a sign of numerous inclusions derivative from the chronic inflammation, may be pus. This indicator at odontogenic sinusitis was revealed only in $1(5,5 \pm 5,1 \%)$ patient. Hypoechogenic component that indicate the presence of cystic changes and liquid in the mucous tunic $(5,5 \pm 5,1 \%)$ was revealed more often than at iatrogenic sinusitis $(p>0,05)$.

At the same time at both described forms of stomatogenic sinusitis mainly mucous tunic of maxillary sinus had even thickening and the shadow of the back wall at visualization - the arched form (Table 5).

Thus, sonographic picture of two the most spread etio-pathogenetic forms of stomatogenic maxillary sinusitis: odontogenic and iatrogenic ones reflect the features of their pathogenesis and clinical course [19].

\section{Conclusions}

1. Sonographic picture of maxillary sinuses at stomatogenic maxillary sinusitis depends on etio-pathogenetic forms of disease.

2. For iatrogenic form of maxillary sinusitis of stomatogenic origin are typical the ultrasound signs of chronic inflammation with numerous inclusions in sinus of inflammatory origin, sclerosis of the mucous tunic and serous effusion. By frequency prevailed: hyperechogenicity of membrane $(39,7 \pm 5,9 \%)$, its heterogenous structure of contents $(35,3 \pm 5,7 \%)$, arched outline of the back wall $(39,7 \pm 5,9 \%)$.

3. For odontogenous form of maxillary sinusitis of stomatogenic origin are typical the ultrasound signs of acute character of acute catarrhal inflammation with predominance of exudation in the depth of mucous tunic and the absence of contents in the lumen of sinus. By frequency prevailed: hypoechogenicity of membrane $(27,8 \pm 10,5 \%)$, its homogenous echostructure $(61,1 \pm 11,4 \%)$; acoustic shadow in sinus $(72,2 \pm 10,5 \%)$, arched character of back wall $(27,8 \pm 10,5 \%)$.

\section{References}

[1] Rosenfeld, R. M., Piccirillo, J. F., Chandrasekhar, S. S., Brook, I., Ashok Kumar, K., Kramper, M. et. al. (2015). Clinical Practice Guideline (Update): Adult Sinusitis. Otolaryngology - Head and Neck Surgery, 152, S1-S39. doi: 10.1177/0194599815572097

[2] Shilenkova, V. V., Kozlov, V. S., Byirihina, V. V. (2006). Two-dimensional ultrasound diagnosis of paranasal sinuses. Yaroslavl, 54.

[3] Sato, H. (2006). Closure of a fistula of the maxillary sinus and oral cavity. Shiyo, 34 (1), 945-951. 
[4] Klyonkina E. I. (2011). Differential diagnostic aspects of latent and chronic odontogenic maxillary sinusitis rhinogenous. Sankt-Peterburg, 20.

[5] Varzhapetyan, S. D. (2015). Justification of the choice of methods for initial evaluation of patients with iatrogenic maxillary sinusitis.Voprosi teoreticheskoy i klinicheskoy meditsinyi, 18/2 (98), 43-48.

[6] Babkina, T. M., Demidova, E. A. (2013). Optimization of radiation diagnosis of odontogenic sinusitis. VIsnik stomatologiyi, 3, 42-48.

[7] Varzhapetyan, S. D., Gulyuk, A. G., Farenyuk, O. A. (2013). The use of different radiological methods in the diagnosis of maxillary sinusitis. Visnik stomatologiyi, 3, 38-41.

[8] Fufezan, O., Asavoaie, C., Cherecheş, P. P. (2010). The role of ultrasonography in the evaluation of maxillary sinusitis in pediatrics. Med Ultrason, 12 (1), 4-11.

[9] Haapaniemi, J., Laurikainen, E. (2001). Ultrasound and antral lavage in the examination of maxillary sinuses. Rhinology, 39 (1), 39-42.

[10] Zasteba, T. A. (2004). Ultrasonography in inflammatory diseases of the maxillary sinuses. Tashkent, 18.

[11] Birikhina, V. V. (2007). Two-dimensional ultrasound diagnosis of diseases of the paranasal sinuses. Moscow, 26.

[12] Risavi, R., Klapan, I., Barcan, T., Simović, S. (1998). Effectiveness of ultrasonography in diagnosis of maxillary sinus disease: a prospective comparison with radiographic and sinusoscopic examinations. Croat Med. J.,39 (1), 45-48.

[13] Shapiro, G., Furukawa, C., Pierson, W., Gilbertson, E., \& Bierman, C. (1986). Blinded comparison of maxillary sinus radiography and ultrasound for diagnosis of sinusitis. Journal of Allergy and Clinical Immunology, 77 (1), 59-64. doi: 10.1016/0091-6749(86)90324-6

[14] Varonen, H., Mäkelä, M., Savolainen, S., Läärä, E., Hilden, J. (2000). Comparison of ultrasound, radiography, and clinical examination in the diagnosis of acute maxillary sinusitis. Journal of Clinical Epidemiology, 53 (9), 940-948. doi: 10.1016/s0895-4356(99)00213-9

[15] Pukhlik, S. M., Buchatskiy, M. S. (2013). Modern imaging techniques condition of the paranasal sinuses. The experience of ultrasound diagnosis. Rinologiya, 2, 58-64.

[16] Shilenkova, V. V. (2008). Acute and recurrent sinusitis in children (diagnosis and treatment). Moscow, 43.

[17] Jehogennost' i jehostruktura. Uzly shhitovidnoj zhelezy. Available at: http://uzlovoyzob.com/ -q-q/66-21-.html

[18] Varzhapetyan, S. D. (2016). Clinical and radiographic parallels some forms of iatrogenic maxillary sinusitis. Wschodnieuropejske Czasopismo Naukowe, 5, 72-79.

[19] Gulyuk, A. G., Varzhapetyan, S. D. (2015). Justification Classification of iatrogenic maxillary sinusitis somatogenic origin. Innovatsiyi v stomatologiyi, 2, 27-38. 